\title{
Custos da Qualidade: Obrigatoriedade de Mensuração nos Sistemas da Qualidade Certificados com Base nas Normas ISO
}

\author{
Elisandra Collaziol \\ Mestrado em Ciências Contábeis pela Universidade do Vale do Rio dos Sinos - \\ UNISINOS \\ Professora da Universidade do Vale do Rio dos Sinos - UNISINOS \\ Avenida Unisinos, 950. Bairro Cristo Rei. São Leopoldo/RS. CEP: 93022-750 \\ E-mail: eliscollaziol@unisinos.br
}

Marcos Antonio de Souza Doutorado em Controladoria e Contabilidade pela Universidade de São Paulo - USP Professor da Universidade do Vale do Rio dos Sinos - UNISINOS Avenida Unisinos, 950. Bairro Cristo Rei. São Leopoldo/RS. CEP: 93022-000 E-mail:marcosas@unisinos.br

Clóvis Antônio Kronbauer Doutorado em Contabilidade e Auditoria pela Universidade de Sevilha (Espanha) Professor da Universidade do Vale do Rio dos Sinos - UNISINOS Avenida Unisinos, 950. Bairro Cristo Rei. São Leopoldo/RS. CEP: 93022-000 E-mail: clovisk@unisinos.br

\section{RESUMO}

O objetivo deste estudo é verificar o entendimento das empresas certificadoras quanto a obrigatoriedade de mensuração dos custos da qualidade por empresas certificadas no âmbito das normas ISO. Sobre o assunto há uma vasta literatura enfatizando os benefícios organizacionais decorrentes da mensuração dos custos da qualidade, além de ser ela um pré-requisito para um eficaz sistema de planejamernto e controle da qualidade de produtos e serviços. O estudo, realizado no primeiro semestre de 2007, classifica-se como uma pesquisa exploratória quanto aos seus objetivos e qualitativa quanto à abordagem do problema. Quanto aos procedimentos técnicos caracteriza-se como uma survey, com a utilização de questionários para coleta de dados. A população é formada por empresas certificadoras credenciadas junto ao INMETRO. Quanto aos principais resultados, verificou-se o consenso quanto ao entendimento da não obrigatoriedade de mensuração dos custos da qualidade para certificação do sistema da qualidade pelas normas ISO, tratando-se apenas de uma opção à disposição dos gestores. A obrigatoriedade desse procedimento, segundo parte das certificadoras, ocorre somente quando esse requisito faz parte do projeto e objetivos estabelecidos pela empresa certificada.

Palavras-chave: Custos da Qualidade. Mensuração. Certificação ISO. 
Custos da Qualidade: Obrigatoriedade de Mensuração nos Sistemas da Qualidade Certificados

com Base nas Normas ISO

Elisandra Collaziol, Marcos Antonio de Souza, Clóvis Antônio Kronbauer

\title{
Costs of Quality: Measurement Obligatoriness in Certified Systems Based on ISO Rules
}

\begin{abstract}
The objective of this paper is to verify the agreement between certifiers companies about the obligatoriness of measurement the costs of quality by certified companies in the scope of ISO rules. There is a vast literature emphasizing the organizations benefits by the measurement the quality costs, considered as a prerequisite for an efficient system of planning and control of products and services quality. The study, carried through in the first semester of 2007, is classified as a exploratory research under qualitative analysis of the problem. Beyond this, the research is characterized as a survey, using a questionnaire for the data collection. The population is formed by ISO companies certifiers registered in INMETRO cadastre. The main results demonstrated a consensus about the not obligatoriness of measurement of quality costs for certification the quality system under ISO norms. The obligatoriness of this procedure, according to part of certifiers companies researched, only occurs when this requirement is part of the project and objectives established by own certified company.
\end{abstract}

Keywords: Quality Cost. Measurement. ISO Certification System

\section{INTRODUÇÃO}

Com o objetivo de criar prescrições e parâmetros comuns que pudessem facilitar o intercâmbio global, a International Organization for Standardization (ISO) emitiu normas internacionais sobre sistemas de qualidade: as normas da série ISO 9000.

Além de criar as prescrições e parâmetros, a normalização também é utilizada para a redução de custos. Conforme enfatiza Oliveira e Melhado (2004, p. 58), "a normalização é utilizada cada vez mais como um meio para se alcançar a redução de custo da produção e do produto final, mantendo ou melhorando sua qualidade".

Após o advento de reformulação das normas da ISO 9000, ocorrida em 2000, a mensuração dos custos da qualidade ganhou destaque. Conforme estabelecido no item 5.4.1 da NBR ISO 9001:2000 (p. 5), que trata dos objetivos da qualidade "os objetivos da qualidade devem ser mensuráveis e coerentes com a política de qualidade". 
Custos da Qualidade: Obrigatoriedade de Mensuração nos Sistemas da Qualidade Certificados com Base nas Normas ISO Elisandra Collaziol, Marcos Antonio de Souza, Clóvis Antônio Kronbauer

Complementando, a NBR ISO 9004 (p. 33) destaca que convém às empresas demonstrar e evidenciar a melhoria do sistema de gestão da qualidade também no aspecto financeiro:

Convém que a direção considere a conversão de dados de processo em informações financeiras para fornecer medidas comparáveis ao longo dos processos e para facilitar melhorias da eficácia e eficiência da organização. Exemplos de medidas financeiras incluem: análise dos custos de prevenção e de avaliação; análise dos custos de não-conformidades; análise dos custos das falhas internas e externas; análise dos custos do ciclo de vida.

Outras normas de qualidade, a exemplo da QS 9000 (utilizada no setor automotivo e desenvolvida a partir da interpretação dada à ISO 9000) tratam expressamente da obrigatoriedade da mensuração dos custos da qualidade.

Ao abordar os custos da qualidade como direcionadores para a implementação da ISO 9000, Shepherd (1998) destaca que a empresa BRI International orienta a inclusão obrigatória dos custos da qualidade como requisito para o padrão ISO.

Hansen e Mowen (2001) enfatizam que o uso de informações dos custos da qualidade para implementar e monitorar a eficácia dos programas de qualidade é apenas um dos usos de um sistema de custos da qualidade, podendo ser fonte de dados para tomada de decisões gerenciais, e importantes para partes externas, quando estas avaliam a qualidade da empresa por meio de programas como a ISO 9000 .

Diante dessa realidade, o problema dessa pesquisa assim se apresenta: qual a obrigatoriedade, sob a ótica das empresas certificadoras, da mensuração dos custos da qualidade nos sistemas de qualidade implantados no âmbito das normas ISO 9000? Além de possibilitar avaliar o aspecto compulsório da mensuração, o estudo oportuniza a identificação de alguns dos possíveis motivos da não adoção, pelas empresas, dessa prática tão enfatizada pela literatura pertinente. 
Custos da Qualidade: Obrigatoriedade de Mensuração nos Sistemas da Qualidade Certificados com Base nas Normas ISO Elisandra Collaziol, Marcos Antonio de Souza, Clóvis Antônio Kronbauer

\section{REFERENCIAL TEÓRICO}

\subsection{Normalização da Série ISO 9000}

Com a globalização e fortalecimento da economia mundial, reduziram-se as barreiras tarifárias e estabeleceram-se barreiras não-tarifárias, ou barreiras técnicas, que se relacionam com a conformidade dos produtos, com o intuito de avaliá-los, conforme ilustrado na Figura 1 (INMETRO, 2002).

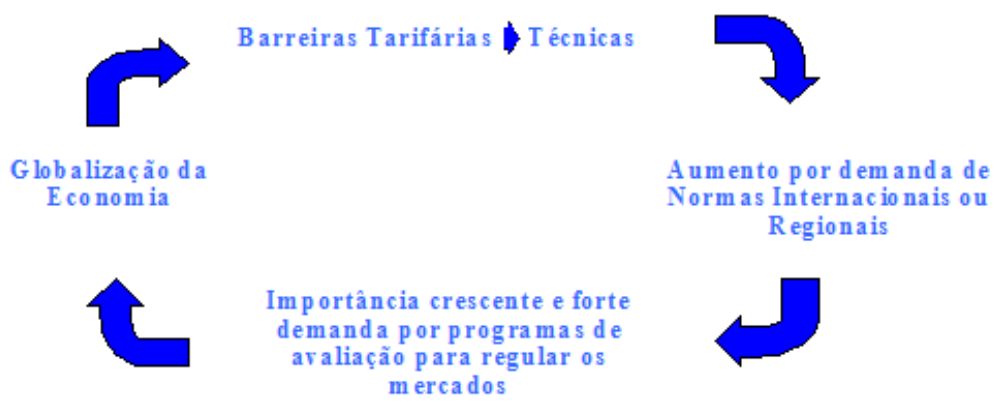

Figura 1: Transição Barreiras Tarifárias para Barreiras Técnicas Fonte: Adaptado de INMETRO (2002, p.4).

Dessa forma, a normalização surgiu da necessidade de nivelamento de rotinas e procedimentos referentes à qualidade, em virtude das diferenças e particularidades dos países, com a finalidade de estruturar uma padronização e criar um modelo internacional para a qualidade, minimizando os impactos das barreiras técnicas (OLIVEIRA; MELHADO, 2004). A criação da Organização Internacional para Normatização, do inglês, International Organization for Standardization (ISO) ratifica tal entendimento.

Oliveira e Melhado (2004) destacam que a ISO é uma entidade não governamental, criada em 1947, com sede em Genebra, Suíça. Ela tem como objetivo promover o desenvolvimento da normalização e atividades relacionadas com a intenção de facilitar o intercâmbio internacional de bens e desenvolver a cooperação nas esferas intelectual, científica, tecnológica e de atividade econômica. Como decorrência, tem-se o surgimento das normas ISO, as quais representam um padrão mundial de referência em relação à gestão da qualidade. 
Custos da Qualidade: Obrigatoriedade de Mensuração nos Sistemas da Qualidade Certificados com Base nas Normas ISO Elisandra Collaziol, Marcos Antonio de Souza, Clóvis Antônio Kronbauer

$\mathrm{Na}$ realidade, a certificação não é concedida pela ISO, que é uma entidade normalizadora internacional, mas sim pelos representantes das entidades máximas de normalização nos respectivos países associados.

No Brasil, o órgão representante é a Associação Brasileira de Normas Técnicas (ABNT), cabendo ao Instituto Nacional de Metrologia, Normalização e Qualidade Industrial (INMETRO), credenciador oficial do Estado brasileiro, o credenciamento dos órgãos certificadores.

A função destes órgãos é assegurar que os processos da empresa estejam sendo executados de forma controlada, e de acordo com as especificações das normas. Assim, a série ISO 9000 consiste num conjunto de normas que especifica requisitos para um sistema de gestão de qualidade:

A filosofia das normas de gestão é, em geral, a de induzir à organização por processos (...). No entanto, as normas de sistema de gestão não ditam qual o produto a ser produzido ou como produzi-lo, mas apenas como estruturar os sistemas de gestão da organização, de forma a assegurar a repetibilidade dos resultados obtidos, no que diz respeito ao parâmetro qualidade (INMETRO, 2002, p.11).

Complementando o entendimento do INMETRO, Oliveira (apud ANDRADE, 2003) enfatiza que o fato de produtos serem fabricados em um processo certificado pelas normas da ISO, não significa que terão mais qualidade do que outros similares, mas sim que todos os produtos fabricados neste processo terão as mesmas especificações e o mesmo padrão de qualidade.

A primeira versão da NBR ISO 9000 foi desenvolvida em 1994 e era composta pelas normas ISO 9000 e 9004, que tratavam das diretrizes, e pelas normas ISO 9001 a 9003, que estabeleciam normas contratuais ou normas certificadoras.

Em 2000 as normas foram revisadas e, então, publicada a nova série de normas ISO 9000. Segundo Oliveira e Melhado (2004), por meio de uma pesquisa conduzida pela própria ISO, foi constatado junto aos usuários que as normas eram confusas, pesadas e continham um forte viés de manufatura. Com a nova versão, 
Custos da Qualidade: Obrigatoriedade de Mensuração nos Sistemas da Qualidade Certificados com Base nas Normas ISO

Elisandra Collaziol, Marcos Antonio de Souza, Clóvis Antônio Kronbauer

deixaram de existir as normas certificadoras 9002 e 9003, ficando assim disposta a nova série das normas ISO 9000:

a) ISO 9000 (Sistema de gestão da qualidade: fundamentos e vocabulário): descreve os fundamentos e terminologias para os sistemas de gestão da qualidade;

b) ISO 9001 (Sistema de gestão da qualidade: requisitos): especifica requisitos para um sistema de gestão da qualidade que podem ser usados pelas empresas para aplicação interna, para certificação ou para fins contratuais, quando uma organização precisa demonstrar sua capacidade para fornecer produtos que atendam aos requisitos do cliente;

c) ISO 9004 (Sistema de gestão da qualidade: diretrizes para melhoria de desempenho): fornece uma orientação com objetivos mais amplos, especificamente a melhoria contínua do desempenho da empresa e sua eficiência, assim como sua eficácia.

A principal mudança está no foco das normas, que deixaram de dar ênfase à documentação e passaram a evidenciar o processo e o comprometimento da administração, visando à melhoria contínua e à satisfação do cliente (LUZ, 2002).

A Figura 2 apresenta o modelo de um sistema de gestão da qualidade baseado em processo, e abordado pelas normas da série ISO 9000.

Verifica-se na Figura 2 o fluxo da eficiência do processo, onde clientes e outras partes interessadas, através dos requisitos que atendam suas expectativas (inputs), alimentam o processo com informações. Tais informações combinadas com os recursos geram as saídas (outputs). Entende-se também que a eficiência acaba por refletir no resultado deste processo, ou seja, ela é o melhor uso dos recursos disponíveis.

A nova abordagem dada pelas normas da série ISO 9000:2000 está representada na parte superior da Figura 2: a direção passa a estar comprometida com o cliente e com a qualidade a ele oferecida, ao passo que deve gerir seus recursos de maneira eficiente na realização do produto e/ou serviço oferecido, medindo e analisando os processos com o intuito de melhorá-los continuamente para satisfazer o seu cliente. 


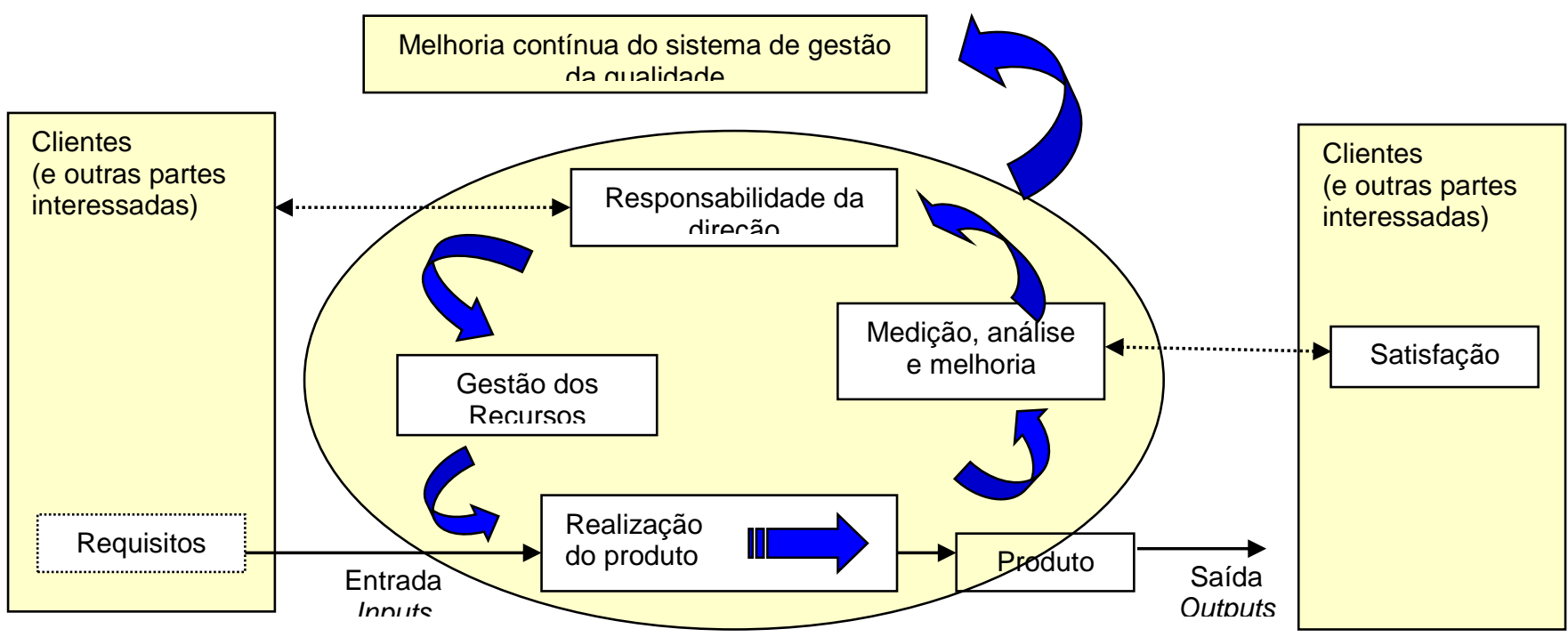

Legenda:

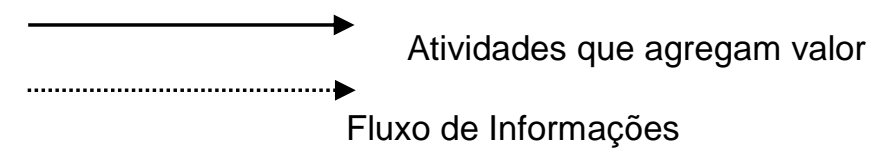

Figura 2: Modelo de um Sistema de Gestão da Qualidade baseado em Processo Fonte: Adaptado da NBR ISO 9000; 2000, p. 4.

É enfatizada na Figura 2 a inter-relação da medição, análise e melhoria, com a satisfação do cliente, e deste para com a empresa. É a eficácia da gestão da qualidade, o cumprimento dos objetivos com o uso eficiente dos recursos. Essa interpretação também é dada por Lyra $(2003$, p. 3) ao afirmar que

a intenção da norma é incentivar a adoção da abordagem de processo nas organizações para o desenvolvimento, implementação e melhoria da eficácia de um sistema de gestão de qualidade visando atender os requisitos dos clientes e conseqüentemente aumentando sua satisfação.

Porém, a normalização da ISO 9000, segundo Barros (1993), não produzirá qualidade de forma isolada, sendo apenas uma referência para o que deve ser feito. A grande questão é como fazer, e isto a própria empresa deve descobrir através dos recursos e ferramentas disponíveis, que são analisados posteriormente neste estudo. 
Custos da Qualidade: Obrigatoriedade de Mensuração nos Sistemas da Qualidade Certificados com Base nas Normas ISO

Elisandra Collaziol, Marcos Antonio de Souza, Clóvis Antônio Kronbauer

Diante deste fato, Alencar (2002) enfatiza que a busca pela certificação tem sido alvo de críticas, pois muitas empresas procuram certificar-se mais pela exigência dos clientes do que pelo real interesse pela qualidade. Apesar de se entender que as exigências dos clientes são indutores de melhorias, para o autor há uma diferença central entre certificação e gerenciamento da qualidade: o gerenciamento da qualidade exige um contínuo aperfeiçoamento dos processos, enquanto que a certificação é aplicada de forma a apenas manter o estágio atual do processo, ou seja, não provoca melhorias. Corroborando este entendimento, Shepherd (1998) argumenta que muitas empresas só implementaram sistemas da qualidade por pressão de mercado, e não por iniciativa própria.

Em suma, a certificação isoladamente não presume qualidade, tampouco se a empresa está de fato buscando a melhoria contínua de seus processos. Ao buscar a certificação, devido à pressão de clientes, ou para se adequar ao mercado, sem o objetivo de gerenciamento da qualidade e dos custos inerentes a esta, as empresas até podem ter benefícios pela implantação de sistemas de qualidade, mas podem também estar somente incorrendo em mais custos. A fim de verificar se há perdas ou ganhos com a qualidade, deve-se entender os processos e o impacto dos custos sobre os mesmos, o que só é possível através do gerenciamento da qualidade, que pressupõe o planejamento, execução e controle. Frisa-se que o controle se dá por meio da mensuração e comparação do previsto (planejado) e do realizado.

\subsection{Relação entre a NBR ISO 9001 e NBR ISO 9004}

Conforme a própria NBR ISO 9001:2000 (p. 3), as edições das NBR ISO 9001 e NBR ISO 9004 "foram desenvolvidas como um par coerente de normas de sistema de gestão da qualidade, as quais foram projetadas para se complementarem mutuamente, mas também podem ser usadas independentemente".

É ainda destacado que a NBR ISO 9001 pode ser usada para aplicação interna, para certificação ou para fins contratuais entre fornecedores e clientes. A principal diferença entre elas é que a NBR ISO 9004 fornece orientações para um sistema de gestão de qualidade com objetivos mais amplos, para empresas que buscam a 
melhoria contínua do desempenho, não tendo propósitos de certificação ou finalidade contratual. Segundo o Manual de Avaliação de Conformidade do INMETRO (2002), os requisitos para implantação do sistema de qualidade seguindo a NBR ISO 9001 são complementados pelas NBR ISO 9000 e 9004.

É uma falha da série das normas ISO 9000 permitir o uso isolado da NBR ISO 9001 para fins de certificação, visto que a mesma, embora destaque a melhoria contínua e a eficácia do sistema de gestão de qualidade, não faz referência aos custos da qualidade, o que só é feito pela NBR ISO 9004. Afinal, empresas são entidades econômicas e, para avaliar a eficácia dos processos, não basta somente a mensuração em termos físicos, sendo também necessário mensurar o resultado econômico. Confirmando este entendimento sobre eficácia, o Sistema de Gestão Econômica - GECON, afirma que o lucro é a melhor medida de desempenho (PEREIRA, 2001).

Assim, para avaliar a eficácia do sistema de gestão de qualidade, além dos parâmetros físicos, é necessário também mensurar os custos da qualidade, o que é recomendado somente pela NBR ISO 9004, no item 8.2.1.4.

Araújo (2001, p. 50) corrobora ao afirmar que "a gestão e mensuração dos custos da qualidade têm como objetivo avaliar a eficácia dos custos da gestão de qualidade da firma".

Convém que a direção considere a conversão de dados de processo em informações financeiras para fornecer medidas comparáveis ao longo dos processos e para facilitar melhorias da eficácia e eficiência da organização. Exemplos de medidas financeiras incluem: análise dos custos de prevenção e de avaliação; análise dos custos de não-conformidades; análise dos custos das falhas internas e externas; análise dos custos do ciclo de vida (NBR ISO 9004:2000, p.33).

A necessidade de complementação é mais uma vez constatada, já que a NBR ISO 9004 não tem propósitos de certificação ou finalidade contratual. Embora com objetivos mais amplos que a NBR ISO 9001, almeja a melhoria contínua de sua eficiência e eficácia. 
Custos da Qualidade: Obrigatoriedade de Mensuração nos Sistemas da Qualidade Certificados com Base nas Normas ISO

Elisandra Collaziol, Marcos Antonio de Souza, Clóvis Antônio Kronbauer

Neste sentido, e procurando dar mais embasamento teórico à necessidade da mensuração dos custos da qualidade, será abordado no próximo tópico a melhoria contínua da eficiência e eficácia, e sua relação com as normas NBR ISO 9001 e 9004.

\subsection{Melhoria Contínua da Eficiência e Eficácia}

O Bureau Veritas do Brasil (2002, p.11) define eficiência como a "relação entre o resultado alcançado e os recursos usados" e eficácia como a "extensão na qual as atividades planejadas são realizadas e os resultados planejados são atingidos".

Em síntese, pode-se equacionar os conceitos de eficiência e eficácia da seguinte forma:

\section{EFICIÊNCIA $=\quad$ Resultado alcançado \\ Recursos consumidos \\ EFICÁCIA $=\quad$ Resultados atingidos \\ Resultados planejados}

Com o mesmo entendimento manifesta-se Padoveze (2003), ao afirmar que a eficácia ocorre quando os objetivos preestabelecidos são atingidos como resultado da atividade ou do esforço, quando a organização cumpre a sua missão, e eficiência é a relação existente entre o resultado obtido e os recursos consumidos para conseguí-lo. Assim, a eficiência por si só não garante a eficácia, mas é imprescindível para alcançá-la.

Pereira (2001) apresenta os conceitos de eficácia e eficiência, os quais podem ser sintetizados da seguinte forma: 
Custos da Qualidade: Obrigatoriedade de Mensuração nos Sistemas da Qualidade Certificados com Base nas Normas ISO Elisandra Collaziol, Marcos Antonio de Souza, Clóvis Antônio Kronbauer

\begin{tabular}{|l|l|}
\hline \multicolumn{1}{|c|}{ EFICIENCIA } & \multicolumn{1}{c|}{ EFICACIA } \\
\hline $\begin{array}{l}\text { Consumo ótimo de recursos } \\
\text { por unidades produzidas }\end{array}$ & Maximizar resultados \\
\hline Ênfase nos meios & Énfase nos resultados \\
\hline Fazer corretamente as coisas & Fazer as coisas corretas \\
\hline Resolver problemas & Atingir objetivos \\
\hline Salvaguardar recursos & Otimizar a utilização dos recursos \\
\hline Cumprir tarefas/obrigações & $\begin{array}{l}\text { Cumprir a missão e assegurar a } \\
\text { continuidade }\end{array}$ \\
\hline
\end{tabular}

Quadro 1 - Quadro Comparativo: Eficiência x Eficácia Fonte: Adaptado de Pereira (2001)

Comparando os termos eficiência e eficácia, conclui-se que a eficiência está relacionada ao consumo ótimo dos recursos para alcançar a eficácia, ou seja, o resultado.

A NBR ISO 9001:2000 (p. 3) "está focada na eficácia do sistema de gestão de qualidade" e direciona a implementação do mesmo, no sentido de melhorar continuamente seu resultado, conforme pode ser constatado em outros trechos da norma: " a organização deve estabelecer, documentar, implementar e manter um sistema de gestão de qualidade e melhorar continuamente a sua eficácia (p.4); a alta direção deve fornecer evidência (...) com a melhoria contínua de sua eficácia (p.5)". Conforme abordado no tópico 2.2. deste estudo, e de acordo com o item 0.3 da NBR ISO 9001, a NBR ISO 9004 almeja a melhoria contínua do desempenho. Araújo (2001, p. 9) assim conceitua desempenho: "resultado das ações empreendidas pelos gestores de uma empresa em busca da eficácia organizacional".

Assim, a melhoria contínua do desempenho almejada pela NBR ISO 9004:2000, constitui-se na melhoria contínua da eficácia focada pela NBR ISO 9001:2000. Portanto, as empresas certificadas pela NBR ISO 9001 deveriam utilizar a NBR ISO 9004 para a melhoria contínua da eficácia, devendo demonstrar e evidenciar esta melhoria em seu sistema de gestão de qualidade, inclusive no aspecto financeiro, conforme prescrito no item 8.2.1.4, citado no tópico anterior deste estudo.

Esta evidência também pode ser comprovada no item 5.4.1 da NBR ISO 9001:2000 (p. 5), que trata dos objetivos da qualidade, ao destacar que "os objetivos da qualidade devem ser mensuráveis e coerentes com a política de qualidade". 
Custos da Qualidade: Obrigatoriedade de Mensuração nos Sistemas da Qualidade Certificados com Base nas Normas ISO Elisandra Collaziol, Marcos Antonio de Souza, Clóvis Antônio Kronbauer

Sendo a eficácia a finalidade maior, os objetivos que a empresa se propõe a atingir na busca pela maximização dos resultados, e de acordo com o item 5.4.1 citado anteriormente, conclui-se que os objetivos da qualidade devem ser mensurados também financeiramente.

Corroborando tal entendimento, Oliveira e Melhado (2004) afirmam que não há como ter certeza da melhoria do Sistema de Gestão da Qualidade (SGQ), nem ter responsabilidade ou motivação para buscar os objetivos da qualidade, sem que os mesmos sejam claros e mensuráveis, e isso aplica-se tanto a indicadores físicos como financeiros, sendo nestes últimos incluídos os custos da qualidade.

Para Hansen e Mowen (2001), relatar e mensurar o desempenho da qualidade, mediante a mensuração dos custos da qualidade, é absolutamente essencial para o sucesso de um programa contínuo de melhoria da qualidade. Na mesma linha de entendimento Wernke (2000, p. 6), assim se manifesta:

Depois de conseguida a certificação e até mesmo antes desta, os custos da qualidade devem ser identificados e mensurados para servirem como um direcionador de ações de melhoria e até como incentivo à continuidade do programa de qualidade, visto que se constituem de resultados práticos em termos de visualização e entendimento dos envolvidos.

É neste sentido que Moori e Silva (2001) afirmam que, após o advento da nova versão 2000 , "o sistema de mensuração de custos da qualidade é um item obrigatório para a certificação de qualidade".

Com este mesmo entendimento é que uma empresa de consultoria canadense, a BRI International, tem ajudado diversas empresas a se certificarem pelas normas da ISO 9000 e QS -Quality System - 9000 (SHEPHERD, 1998).

A norma QS 9000 é uma norma de qualidade para o setor automotivo, adotada pelas empresas automobilísticas Chrysler, Ford e General Motors, a qual foi desenvolvida a partir da interpretação dada à ISO 9000. Nela está expressa a obrigatoriedade da mensuração dos custos da qualidade em seu tópico 4.1.4 - Plano 
Custos da Qualidade: Obrigatoriedade de Mensuração nos Sistemas da Qualidade Certificados com Base nas Normas ISO

Elisandra Collaziol, Marcos Antonio de Souza, Clóvis Antônio Kronbauer

de Negócios, onde é determinado que o plano de negócios deve envolver os custos da qualidade (FRANCO, 2001).

Shepherd (1998), ao abordar os custos da qualidade como direcionadores para a implementação da ISO 9000, destaca que a empresa BRI International orienta a inclusão obrigatória dos custos da qualidade como requisito para o padrão ISO.

Entretanto, apesar da exposição explícita quanto aos procedimentos para mensuração dos custos da qualidade, deve ser lembrado que a NBR ISO 9004:2000, de acordo com Oliveira e Melhado (2004, p. 64), "é uma norma que estabelece diretrizes e descreve um conjunto básico de elementos pelos quais o sistema pode ser desenvolvido. Sendo assim, o usuário dessa norma pode selecionar os elementos do sistema da qualidade adequados à sua realidade empresarial".

Aliado ao entendimento de Oliveira e Melhado (2004), destaca-se que a NBR ISO 9004, utiliza os termos "convém" e "pode ser", o que presume a não obrigatoriedade da mensuração dos custos da qualidade.

Independentemente da obrigatoriedade ou não de adoção de tais procedimentos no âmbito das normas ISO, para fins deste estudo prevalece o entendimento de que a eficácia do sistema de gestão da qualidade não pode prescindir de um adequado sistema de planejamento e controle dos custos relacionados.

Ainda há de se destacar que um sistema de qualidade adequado não é formador de custos, muito pelo contrário, é autofinanciável, pois a medida que se reduzem as falhas, se geram recursos para investimento em prevenção da qualidade. Trata-se, pois, de um procedimento sugerido e considerado como recomendável e oportuno.

\section{ASPECTOS METODOLÓGICOS}

Segundo Raupp e Beuren (2003), as pesquisas podem ser classificadas quanto aos objetivos, quanto à abordagem do problema e quanto aos procedimentos técnicos. Quanto aos objetivos a pesquisa é caracterizada como exploratória. Segundo Gil (2001), a pesquisa exploratória visa proporcionar maior familiaridade com o problema, 
Custos da Qualidade: Obrigatoriedade de Mensuração nos Sistemas da Qualidade Certificados com Base nas Normas ISO

Elisandra Collaziol, Marcos Antonio de Souza, Clóvis Antônio Kronbauer

com vistas a torná-lo explícito e com o objetivo de aprimoramento de idéias, ou seja, a principal finalidade é desenvolver, esclarecer e/ou modificar conceitos e idéias.

Quanto a abordagem do problema, a pesquisa é caracterizada como qualitativa, pois descreve a complexidade do problema, sendo os dados analisados e interpretados indutivamente, de forma qualitativa.

Quanto aos procedimentos técnicos a pesquisa se caracteriza como do tipo survey, utilizando-se de um questionário estruturado com questões abertas para coleta de dados.

A população é composta pelas 25 empresas certificadoras existentes em Julho de 2006, credenciadas pelo INMETRO. Delas, 22 se dispuseram a participar da pesquisa. Dos questionários remetidos oito retornaram em condições de uso, representando $32 \%$ da população total e $36,4 \%$ da efetiva.

\section{APRESENTAÇÃO E ANÁLISE DE DADOS}

Apesar da precaução das empresas certificadoras em posicionar-se quanto à obrigatoriedade ou não da mensuração dos custos da qualidade por empresas certificadas pelas normas da série ISO 9000, de maneira geral há um consenso no entendimento das mesmas, quanto a não obrigatoriedade de mensuração dos custos da qualidade para fins de certificação.

Das oito empresas respondentes, seis deixaram muito claro que a mensuração dos custos da qualidade não é um item obrigatório para as empresas que buscam ou pretendem manter a certificação pelas normas da série ISO 9000.

Ainda assim, verificou-se a importância dada pelas certificadoras quanto à obrigatoriedade de mensuração dos custos da qualidade, pois, ao responder a primeira questão, três empresas (13,6\% da amostra) utilizaram termos como: "não exige formalmente", "não é um requisito explícito", ou ainda, "se não puder ser mensurado, de nada adiantará o esforço", deixando claro que, embora não seja obrigatória, a mensuração dos custos da qualidade é importante para a otimização dos processos. 
Custos da Qualidade: Obrigatoriedade de Mensuração nos Sistemas da Qualidade Certificados com Base nas Normas ISO

Elisandra Collaziol, Marcos Antonio de Souza, Clóvis Antônio Kronbauer

Três empresas certificadoras (13,6\% da amostra) responderam que não verificam, quando da certificação, se as empresas que buscam a certificação ou manutenção da ISO mensuram os custos da qualidade, porém a maioria entende que, embora a mensuração dos custos da qualidade não seja um item obrigatório, se for indicado como um dos objetivos do sistema da qualidade ou como indicadores para medição e monitoramento dos processos, será objeto de auditoria, sendo verificados então, a estrutura, a forma de coleta, o método de mensuração e a forma de apresentação.

Em relação a recomendações por parte das certificadoras quanto à mensuração dos custos da qualidade, três respondentes deixaram claro que não o fazem e as demais se manifestaram no sentido de que tudo o que possa implicar oportunidade de melhoria poderá ser recomendado. Uma das empresas respondentes, embora não recomende formalmente a mensuração dos custos da qualidade, afirma existirem comentários que a próxima revisão da norma ISO 9001 passará a exigir este requisito.

Quando questionadas em relação ao conhecimento que tinham sobre a utilização ou não da mensuração dos custos da qualidade, por parte das empresas que buscam a certificação, duas empresas ( $9 \%$ da amostra) declararam não ter conhecimento sobre tal fato, já que este item não era verificado por elas. Três empresas (13,6\% da amostra) esclareceram que a mensuração dos custos da qualidade é feita de forma indireta, através de indicadores físicos, ou seja, embora não utilizem indicadores monetários, fazem uso de indicadores que sinalizam seu desempenho financeiro.

Apenas uma certificadora afirmou que todas as empresas de seu relacionamento mensuram os custos da qualidade, embora tal resposta entre em conflito com a resposta dada à segunda questão, pois a empresa não verifica quando da certificação, se há mensuração dos custos da qualidade.

As certificadoras apontaram os seguintes motivos para a não mensuração dos custos da qualidade são: (1) cultura da empresa e falta de conhecimento a respeito; (2) não exigência da mensuração pelos requisitos atuais da norma ISO 9001; (3) 
Custos da Qualidade: Obrigatoriedade de Mensuração nos Sistemas da Qualidade Certificados com Base nas Normas ISO

Elisandra Collaziol, Marcos Antonio de Souza, Clóvis Antônio Kronbauer

dificuldade de mensuração e falta de recursos de informática que auxiliem na identificação e tratamento dos custos da qualidade.

Em suma, contrariamente ao entendimento de Moori e Silva (2001), ainda não é possível afirmar que a mensuração dos custos da qualidade passou a ser um item obrigatório para a certificação ou manutenção da norma ISO 9001.

Apesar da exposição explícita quanto a procedimentos para mensuração dos custos da qualidade, deve ser lembrado que a NBR ISO 9004:2000, de acordo com Oliveira e Melhado (2004, p. 64), "é uma norma que estabelece diretrizes e descreve um conjunto básico de elementos pelos quais o sistema pode ser desenvolvido". Além disso, destaca-se que a NBR ISO 9004, utiliza os termos "convém" e "pode ser", o que presume a não obrigatoriedade da mensuração dos custos da qualidade.

\section{CONCLUSÃO}

Nesse estudo buscou-se investigar o entendimento das empresas certificadoras das normas ISO, credenciadas pelo INMETRO, quanto à obrigatoriedade de mensuração dos custos da qualidade, por empresas que buscam a certificação ou manutenção da ISO 9001.

Constatou-se, com base na opinião das empresas certificadoras, que não existe a obrigatoriedade de mensuração dos custos da qualidade para fins de certificação ou manutenção da ISO. Para elas, a mensuração dos custos da qualidade somente será objeto de auditoria para certificação ou renovação da ISO, se for adotado formalmente pelas empresas como um indicador do sistema para avaliar a melhoria dos processos.

Embora não seja explícita, a mensuração dos custos da qualidade está implícita nas normas, seja pela complementação que uma norma faz à outra, e pela referência que as mesmas fazem à eficácia dos processos ou, ainda, pelo caráter orientativo da norma ISO 9004:2000. Para as empresas certificadoras, entretanto, isso não é suficiente para criar a obrigatoriedade. Apesar desse consenso entre as certificadoras, observa-se que no entendimento de uma delas, de expressiva atuação no mercado, a obrigatoriedade da mensuração dos custos da qualidade por empresas que buscam a 
Custos da Qualidade: Obrigatoriedade de Mensuração nos Sistemas da Qualidade Certificados com Base nas Normas ISO

Elisandra Collaziol, Marcos Antonio de Souza, Clóvis Antônio Kronbauer

certificação é uma questão de tempo e vai depender da preparação e adaptação das empresas.

Acredita-se que para se tornar um item obrigatório, antes deverão ser sanadas as dificuldades existentes para a não mensuração dos custos da qualidade, apontadas pelas certificadoras como o motivo para a não mensuração.

A cultura, das empresas, pode ser modificada propagando-se mais conhecimento a respeito, seja por meio de pesquisas científicas que requeiram a participação das empresas, seja pela divulgação por parte das entidades envolvidas com a qualidade. Desta forma, ratifica-se a necessidade de novos estudos que possam disseminar e propagar a importância do planejamento, mensuração e controle dos custos da qualidade.

\section{REFERÊNCIAS}

ALENCAR, Roberta Carvalho. (2002). Investigação das Práticas de Mensuração dos Resultados dos Programas de Melhoria de Qualidade: Um estudo exploratório. (Dissertação de Mestrado). Faculdade de Economia Administração e Contabilidade, Universidade de São Paulo - FEA/USP.

ANDRADE, Fábio Fellipe. (2003). O Método de Melhorias PDCA. (Dissertação de Mestrado). Escola Politécnica, Universidade de São Paulo - USP.

ARAÚJO, Aneide Oliveira. (2001). Contribuição o Estudo de Indicadores de Desempenho de Empreendimentos Hoteleiros, sob o Enfoque da Gestão Estratégica. (Tese de Doutorado). Faculdade de Economia Administração e Contabilidade, Universidade de São Paulo - FEA/USP.

Associação Brasileira de Normas Técnicas. (2000). Sistemas de gestão da qualidade Requisitos. NBR ISO 9001: 2000. Rio de Janeiro, ABNT.

. (2000). Sistema de gestão da qualidade: Diretrizes para Melhoria de Desempenho. NBR ISO 9004: 2000. Rio de Janeiro, ABNT.

BARROS, Claudius D'artagnan Cunha. (1993). Sensibilizando para a Qualidade. Rio de Janeiro, Qualitymark.

BUREAU VERITAS DO BRASIL. (2002). Atualização para Auditores ISO 9001: 2000. São Paulo. 
Custos da Qualidade: Obrigatoriedade de Mensuração nos Sistemas da Qualidade Certificados

com Base nas Normas ISO

Elisandra Collaziol, Marcos Antonio de Souza, Clóvis Antônio Kronbauer

FRANCO, Adenilton. (2001). Custos da Qualidade x Sistemas da Qualidade: Como Atender as Novas Exigências das Normas de Sistemas da Qualidade e Visualizar uma Vantagem Competitiva. (Monografia). Curso de Especialização em Administração Financeira. ESAN - Escola Superior de Administração de Negócios, São Paulo.

Instituto Nacional de Metrologia, Normalização e Qualidade Industrial. (2002). Avaliação da Conformidade. Rio de Janeiro, INMETRO.

GIL, Antonio Carlos. (2001). Como elaborar projetos de pesquisa. São Paulo, Atlas.

HANSEN, Don R, MOWEN, Maryanne M. (2001). Gestão de Custos. São Paulo, Pioneira Thompson Learning.

LUZ, Carolina. (2002). Implantação de Programas da Qualidade pela Certificação da ISO 9001 como Diferencial Competitivo para as Organizações. (Dissertação de Mestrado). Programa de Pós-Graduação de Engenharia de Produção, Universidade Federal de Santa Catarina - UFSC.

LYRA, Ricardo Luiz Wüst Corrêa. (2003). Uma Contribuição a Mensuração do Resultado Econômico da Decisão de Investimento em Qualidade em Empresas de Serviços Contábeis: Uma Abordagem da Gestão Econômica. (Dissertação de Mestrado). Faculdade de Economia Administração e Contabilidade, Universidade de São Paulo - USP.

MOORI, Roberto Giro, SILVA, Rubens Vieira. (2001). Um Estudo do Sistema de Gestão dos Custos da Qualidade nas Empresas Químicas do Brasil. In: XXV Enanpad, Campinas.

OLIVEIRA, Otávio J, MELHADO, Silvio B. (2004). Nova Norma ISO 9000 Versão 2000. In: Gestão da Qualidade: Tópicos Avançados. Organizador: Otávio J. Oliveira. São Paulo, Pioneira Thomson Learning.

PEREIRA, Carlos Alberto. (2001). Ambiente, Empresa, Gestão e Eficácia. In: Controladoria: Uma Abordagem da Gestão Econômica - GECON. Organizador: Armando Catelli. (2 ed.). São Paulo, Atlas, p.35-78.

RAUPP, Fabiano Maury, BEUREN, Ilse Maria. (2003). Metodologia da Pesquisa Aplicável às Ciências Sociais. In: Como Elaborar Trabalhos Monográficos em Contabilidade. Organizadora: Ilse Maria Beuren. São Paulo, Atlas.

ROBLES JR., Antonio. (2003). Custos da Qualidade: Aspectos Econômicos da Gestão da Qualidade e da Gestão Ambiental. São Paulo: Atlas. 
SHEPHERD, Nick A. (1998). Cost of quality - and ISO implementation using cost of quality as a driver for effective use of ISO 9000 and 14000. Quality Congress: ASQ's Annual Quality Congress. Milwaukee, p. 776.

TACHIBANA, W.K. (1994). Administração estratégica de custos. In: Congresso Brasileiro de Gestão Estratégica de Custos, I, São Leopoldo. Anais...São Leopoldo, UNISINOS, p. 283-294.

Data de Submissão: 02/12/2008

Data de Aceite: 23/04/2009 